\title{
PEMODELAN PROSES BISNIS DENGAN BPMN UNTUK KEBUTUHAN IMPLEMENTASI ERP DI CV INDOCOCO PASIFIC
}

\author{
Zanuar Rifai ${ }^{1}$, Trias Bratakusuma ${ }^{2}$, Fiby Nur Afiana ${ }^{3}$, Luzi Dwi Oktaviana ${ }^{4}$ dan Ika \\ Romadoni Yunita \\ 1,2,3,4,5 Sistem Informasi \\ Fakultas Ilmu Komputer \\ Universitas Amikom Purwokerto \\ Email : zanuar.rifai@amikompurwokerto.ac.id ${ }^{1}$, brata@amikompurwokerto.ac.id², \\ fiby@amikompurwokerto.ac.id ${ }^{3}$, oktaviana@amikompurwokerto.ac.id ${ }^{4}$, \\ ikarom@amikompurwokerto.ac.id ${ }^{5}$
}

\begin{abstract}
ABSTRAK
Sektor industri di Indonesia mempunyai potensial yang cukup tinggi untuk dieksplorasi baik usaha skala kecil dan menengah dalam upaya untuk meningkatkan ekspor. CV Indococo Pasific adalah usaha yang bergerak di bidang pengolahan kelapa dan termasuk ke dalam kelompok tani. Masalah utama yang dihadapi saat ini dimulai dari belum adanya sistem tracing dari bahan baku di pengrajin, pengepul hingga menjadi suatu produk jadi sehingga tidak bisa melakukan pemeriksaan bila ada barang yang cacat dalam proses produksi dengan skala besar. Untuk dapat memberikan solusi sistem yang tepat, maka peneliti perlu mengetahui terlebih dahulu proses bisnis dari CV Indococo Pasific dimana proses bisnis tersebut menggambarkan kegiatan atau aktivitas bisnis yang dilakukan oleh pelaku bisnis berkaitan pencapaian visi dan misi, pemberian layanan atau penyampaian produk kepada konsumen. Dengan metode penelitian yang digunakan mulai dari pengumpulan data hingga melihat GAP analisis. Penggambaran proses bisnis ini dituangkan pada Business Process Modeling Notation (BPMN), kemudian dilakukan analisis GAP. Dari hasil pendekatan Business Process Modeling Notation (BPMN) terdapat beberapa modul yang ditrancang seperti modul untuk bagian sortir barang, bagian pengovenan solusinya membuat form atau pengukuran penyusutan produk dan bagian packing membuat modul untuk men-generate $\mathrm{QR}$ code produk jadi.
\end{abstract}

Kata Kunci: proses bisnis, BPMN, analisis GAP

\begin{abstract}
The industrial sector in Indonesia has a high enough potential to be explored by both small and medium scale businesses in an effort to increase exports. CV Indococo Pacific is a business engaged in coconut processing and is included in the farmer group. The main problem currently being faced starts from the absence of a tracing system from raw materials in craftsmen, collectors to a finished product so that they cannot check if there are defective goods in the large-scale production process. To be able to provide the right
\end{abstract}


system solutions, researchers need to know in advance the business processes of $C V$ Indococo Pacific where the business processes describe business activities or activities carried out by business people related to achieving vision and mission, providing services or delivering products to consumers. The research method used is starting from data collection to looking at GAP analysis. The description of this business process is stated in the Business Process Modeling Notation (BPMN), then a GAP analysis is carried out. From the results of the Business Process Modeling Notation (BPMN) approach, there are several modules designed such as a module for the sorting section of goods, the solution oven section for making a form or measurement of product depreciation and the packing section making a module for generating the $Q R$ code of the finished product.

Keywords: Business process, BPMN, gap analysis

\section{PENDAHULUAN}

Pemerintah melalui Kementerian Perindustrian terus mendorong perusahaan untuk memajukan bidang industri ketahap selanjutnya agar Indonesia dapat bersaing dengan negara lainnya, salah satunya adalah dengan ekspor. Beberapa sektor industri di Indonesia mempunyai potensial yang cukup tinggi untuk dieksplorasi baik usaha skala kecil dan menengah dalam upaya untuk meningkatkan ekspor. Namun, hingga saat ini yang menjadi kendala bagi para pelaku usaha skala kecil dan menengah adalah standarisasi produk, kesesuaian produk, sertifikasi organik untuk kelompok pertanian hingga masalah perizinan. CV Indococo Pasific adalah usaha yang bergerak di bidang pengolahan kelapa dan termasuk ke dalam kelompok tani. Permasalahan yang dihadapi oleh CV Indococo Pasific untuk memasuki pangsa pasar yang lebih luas khususnya ekspor belum dapat terlaksana karena belum adanya sistem tracing dari bahan baku di pengrajin, pengepul hingga menjadi suatu produk jadi yang siap dipasarkan, CV Indococo Pasific tidak bisa melakukan sertifikasi organik karena belum adanya sistem yang saling berintegrasi, tidak bisa melakukan pemeriksaan bila ada barang yang cacat dalam proses produksi dengan skala besar.

Untuk dapat memberikan solusi sistem yang tepat, maka peneliti perlu mengetahui terlebih dahulu proses bisnis dari CV Indococo Pasific dimana proses bisnis tersebut menggambarkan kegiatan atau aktivitas bisnis yang dilakukan oleh pelaku bisnis berkaitan pencapaian visi dan misi, pemberian layanan atau 
penyampaian produk kepada konsumen dan pelanggan (Dumas, et al., 2013). Proses bisnis dapat dikatakan juga sebagai rangkaian kegiatan yang saling terkait untuk mencapai tujuan bisnis tertentu yang dituntaskan secara berurutan maupun paralel, oleh manusia ataupun sistem, baik di dalam ataupun di luar organisasi. Dari kompleksitas proses bisnis yang terjalin membuat industri mencari metode untuk menggambarkan proses bisnis tersebut (Maleyeff, 2020). Penggambaran proses bisnis ini dituangkan pada Business Process Modeling Notation (BPMN) yang merupakan gambaran dari suatu bisnis proses diagram berdasarkan teknik diagram alur, kemudian dirangkai menjadi model-model grafis dari operasi-operasi bisnis dimana terdapat aktivitas dan kontrol alur yang mendefinisikan urutan kerja (Terminanto \& Hidayanto, 2018; Mirza, 2018). Business Process Modeling Notation (BPMN) membantu stakeholder yang terlibat dalam proses bisnis agar memahami dan mengerti setiap langkah dari proses tersebut, sehingga perusahaan dapat mencapai keuntungan yang maksimal dari pemodelan proses bisnis yang dilakukan. Seluruh tahapan proses akan direkam dan di data dengan baik, sehingga perusahaan dapat fokus mengembangkan bisnis ke pangsa pasar yang lebih luas.

\section{METODE PENELITIAN}

Adapun metode dalam penelitian ini menggunakan kerangka kerja sederhana. Langka-langkah pada gambar 1 menunjukan alur kegiatan penelitian yang dilakukan di CV Indocooc Pasific.

1. Pengumpulan Data

Pengumpulan data adalah aktivitas mencari data yang dibutuhkan dalam rangka mencapai tujuan penelitian. Dalam hal ini peneliti akan mencari data dengan cara wawancara, observasi, dan dokumen.

\section{Business Process Modeling Notation (BPMN)}

Business Process Modeling Notation (BPMN) merupakan penggambaran dari suatu bisnis proses diagram berdasarkan teknik diagram alur, dirangkai untuk membuat model-model grafis dari operasi-operasi bisnis dimana terdapat aktivitas dan kontrol alur yang mendefinisikan urutan kerja (Badr, Abdulkader, 
\& Elabd, 2017; Zafar, et al., 2019). Seluruh informasi yang telah dikumpulkan, peneliti akan membuat pemodelan BPMN sesuai dengan informasi yang telah diberikankan oleh pihak CV Indococo Pasific.

\section{Analisis GAP dengan Fitur Odoo}

Pada proses ini setelah mengetahui BPMN dan activity, maka peneliti akan melakukan analisis pada seluruh bisnis proses dimana seluruh bisnis proses, aktivitas dan informasi sudah terakomodir dalam fitur Odoo yang akan digunakan atau belum.

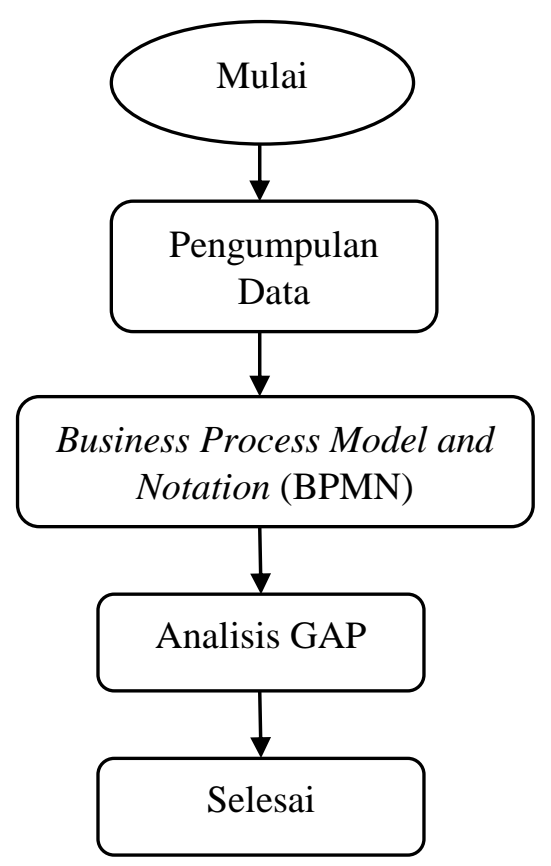

Gambar 1. Metode Penelitian

\section{HASIL DAN PEMBAHASAN}

Business Process Modeling Notation (BPMN) dirancang untuk membantu perusahaan dalam hal ini CV Indococo Pasific dalam menerjemahkan proses bisnis dan mendukung manajemen proses bisnis, baik untuk pengguna teknis dan pengguna bisnis, dengan menyediakan notasi yang intuitif untuk pengguna bisnis, namun dapat mewakili proses yang kompleks. Berikut BPMN yang telah dirancang berdasarkan hasil analisis : 


\section{Business Process Model Notation (BPMN)}

Setelah pengumpulan data berdasarkan wawancara, observasi, dan dokumen yang dilakukan di CV Indococo Pasific maka tahap selanjutnya adalah membuat BPMN.

a. Proses pembelian bahan baku memiliki alur sebagai berikut:

1) Membuat daftar kebutuhan bahan baku, yang meliputi :

(a) Bagian pembelian membuat daftar bahan baku;

(b) Bagian pembelian mencatat bahan baku; dan

(c) Daftar kumpulan bahan baku.

2) Membuat proses pembelian, yang meliputi :

(a) Bagian pembelian membuat purchase order atau order pembelian;

(b) Purchase order dijalankan;

(c) Dilakukan proses pembelian;

(d) Melakukan pembelian barang;

(e) Setelah melakukan pembelian barang (uang sisa atau tidak);

(f) Jika tidak memberikan nota pembelian ke bagian keuangan maka selesai.

(g) Jika sisa, memberikan sisa uang belanja dan nota belanja ke bagian keuangan.

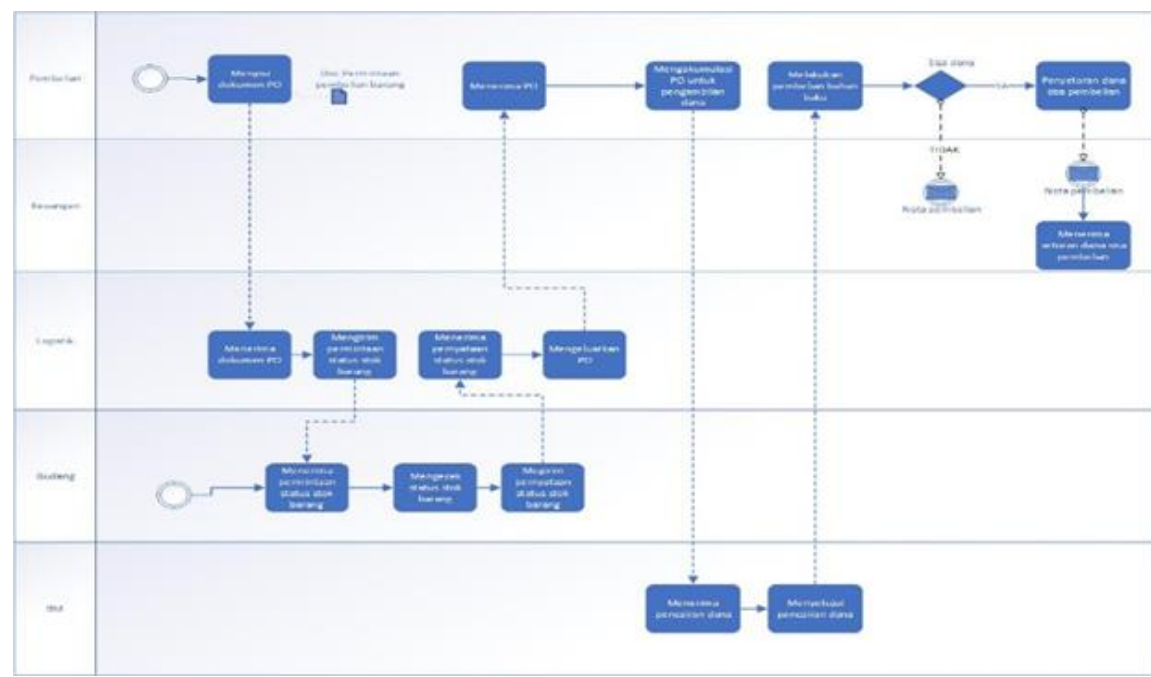

Gambar 2. BPMN Purchase Proses Pembelian 
b. Purchase vendor bill berdasarkan penerimaan barang

Alur BPMN purchase vendor bill berdasarkan penerimaan barang tergambar pada gambar 3 sebagai berikut:

1) Bagian gudang menerima barang;

2) Barang diterima dan laporannya;

3) Bagian pembelian menunggu barang apa saja yang diterima dan laporannya;

4) Daftar barang apa saja yang masuk ke gudang;

5) Pengecekan barang;

6) Jika sesuai maka membuat vendor bill atau tagihan yang harus dibayarkan dan proses selesai;

7) Jika tidak sesuai maka barang dibayar sesuai barang yang datang, atau sesuai barang yang dipesan.

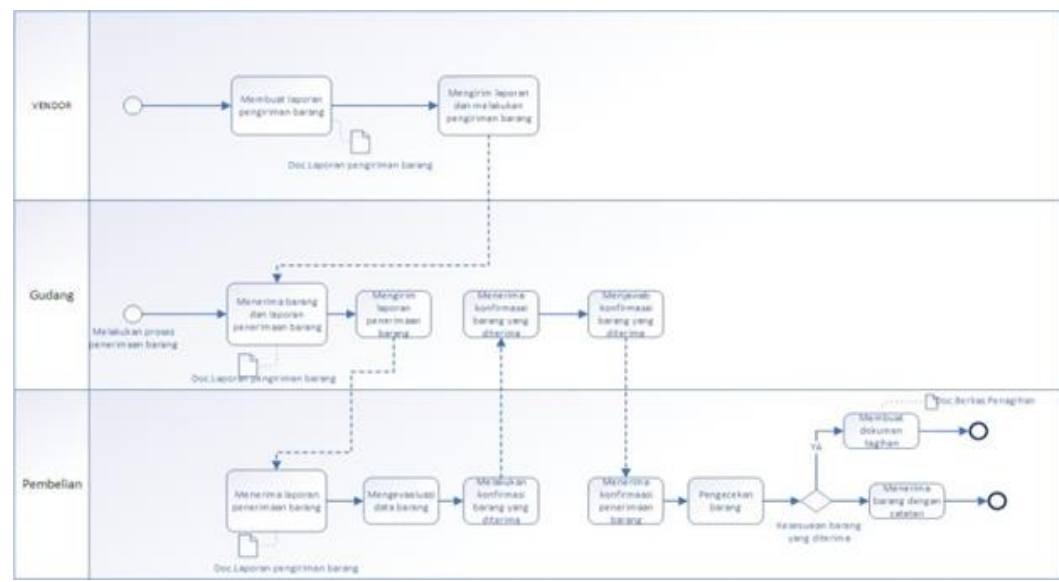

Gambar 3. Purchase Vendor Bill berdasarkan Penerimaan Barang

c. Iventory atau persediaan

Proses bisnis pada inventori untuk bahan baku (raw material) dijabarkan seperti gambar 4 sebagai berikut:

1) Supplier mengantarkan raw material ke pabrik;

2) Admin gudang menerima raw material;

3) Admin gudang menyortir raw material;

4) Raw material layak produksi/jual langsung dilabeli QR Code, atau;

5) Raw material tidak layak produksi/jual dikembalikan ke supplier, atau; 
6) Raw material belum terpenuhi, pabrik melakukan pemesanan kembali ke supplier;

7) Setelah pelabelan, raw material ditimbang dan dikelompokan per-lot;

8) Admin gudang mencatat stok raw material dan menginput data ke sistem;

9) Admin gudang menyimpan stok raw material tersebut.

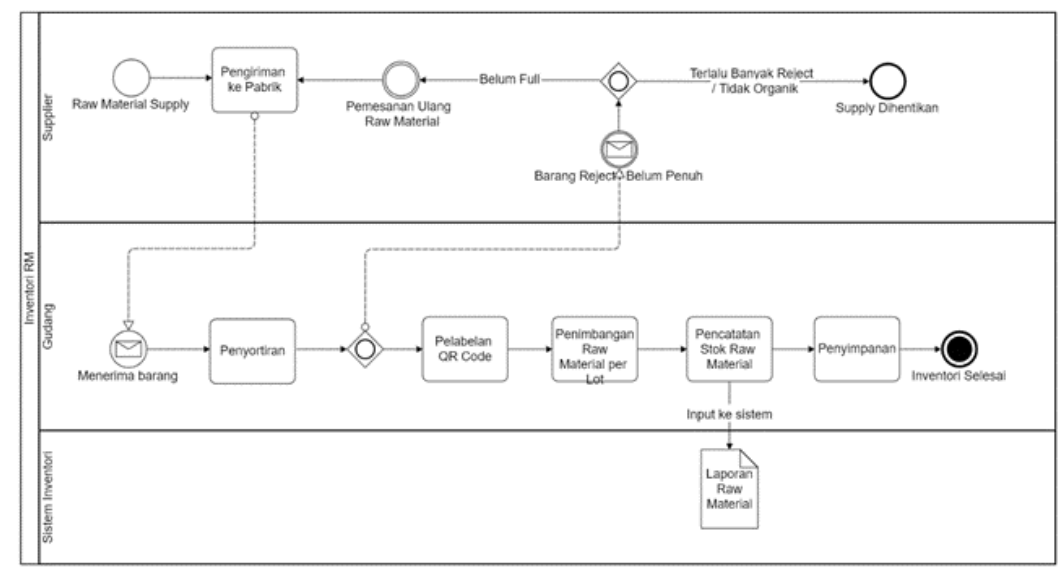

Gambar 4. BPMN Inventori Bahan Baku

Gambar 5, menunjukkan proses bisnis inventori pada produk jadi (finish goods) dan dijelaskan sebagai berikut:

1) Setelah bahan baku diproduksi (dioven/di-packing) produk diserahkan ke gudang;

2) Admin gudang mencatat stok produk;

3) Admin gudang membuat laporan stok produk dan menginputkan ke sistem inventori;

4) Berdasarkan laporan stok, pihak produksi melakukan cek terhadap manufacturing order, jika belum terpenuhi produksi dijalankan kembali;

5) Setelah produk selesai dicatat kemudian produk disimpan hingga menunggu semua manufacturing order terpenuhi. 


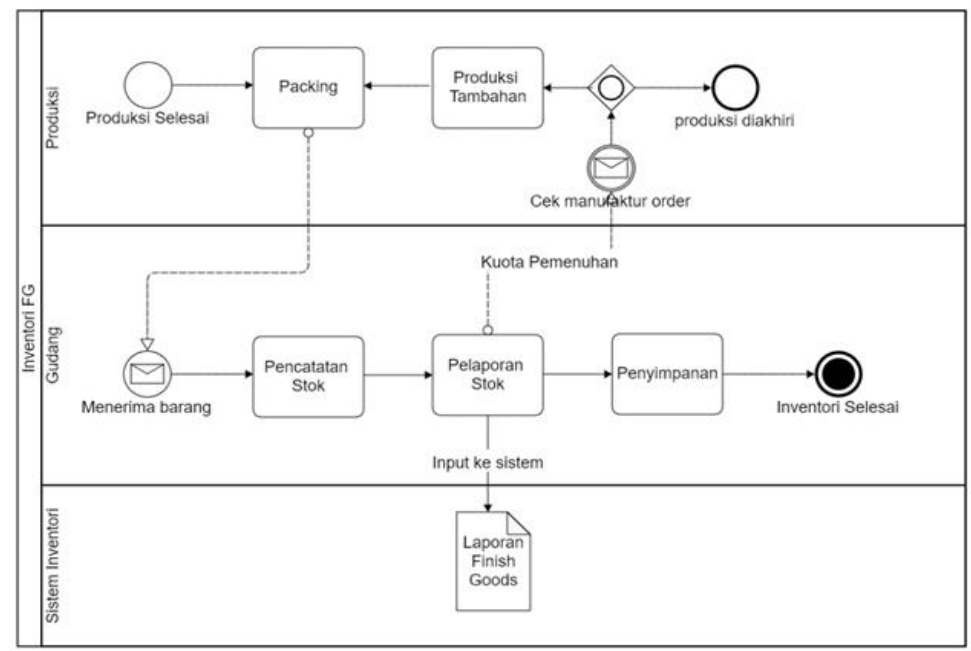

Gambar 5. BPMN Inventori untuk Produk Jadi

Setelah produk jadi (finish goods) diproduksi maka langkah selanjutnya melakukan distribusi produk dengan alur sebagai berikut:

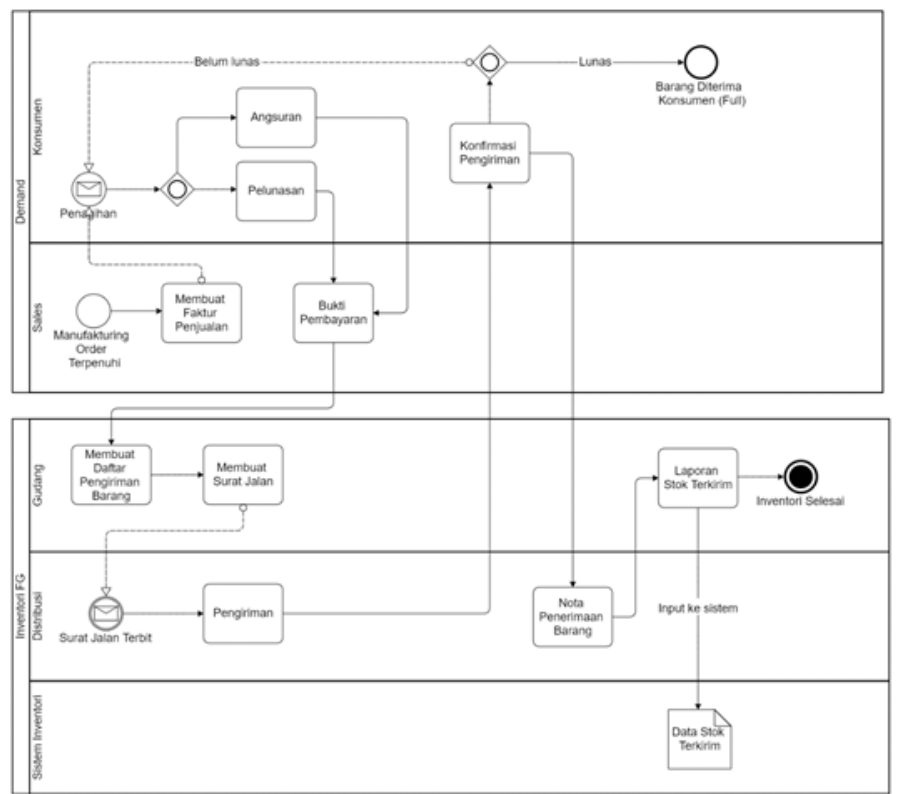

Gambar 6. BPMN Finish Goods yang akan Disitribusikan

Proses bisnis untuk finish goods yang akan didistribusi seperti gambar 5:

1) Pabrik mengkonfirmasi bahwa manufacturing order terpenuhi;

2) Sales membuat faktur untuk penagihan kepada konsumen;

3) Penagihan dikirimkan ke konsumen; 
4) Konsumen bisa melunasi atau melakukan angsuran;

5) Sales mengkonfirmasi pembayaran;

6) Sales menghubungi admin gudang untuk membuat daftar pengiriman barang;

7) Admin gudang membuat surat jalan yang dilampirkan daftar produk yang akan dikirim;

8) Pihak distributor melakukan pengiriman barang ke konsumen;

9) Pihak konsumen mengonfirmasi pesanan yang dikirimkan;

10) Jika belum lunas maka akan diteruskan ke sales untuk penagihan kembali;

11) Distributor juga melaporkan ke pihak gudang bahwa produk telah dikirim;

12) Admin gudang membuat laporan produk yang sudah terkirim dan menginput stok terkirim ke sistem inventori.

d. Proses bisnis Material Requirement Planning (MRP)

Alur proses bisnis MRP pada gambar 7 akan dipaparkan sebagai berikut:

1) Membuat orderan

(a) Pelanggan membuat pesanan lalu menunggu laporan proses produksi;

(b) Sales menerima pesanan;

(c) Sales membuat sales order;

(d) Sales menginformasi proses produksi;

(e) Pelanggan menerima laporan proses produksi;

(f) Pelanggan menunggu untuk menerima pesanan.

2) Manufakturing

(a) Planning menerima orderan;

(b) Planning membuat target estimasi produksi;

(c) Planning menggunakan kode lot dalam proses produksi;

(d) Planning membuat informasi bill of material;

(e) Planning melakukan pembagian raw material per lot; 
(f) Planning melakukan pencatatan stok raw material yang sudah dibagi per lot;

(g) Planning membuat jadwal produksi;

(h) Planning membuat work order;

(i) Planning mengirim informasi work order ke staf produksi;

(j) Staf produksi menerima informasi work order;

(k) Staf produksi melakukan sortir;

(l) Staf produksi menginputkan data/informasi proses sortir barang;

(m) Staf produksi memasukan ke oven atau masuk proses pengepakan tanpa melalui oven.

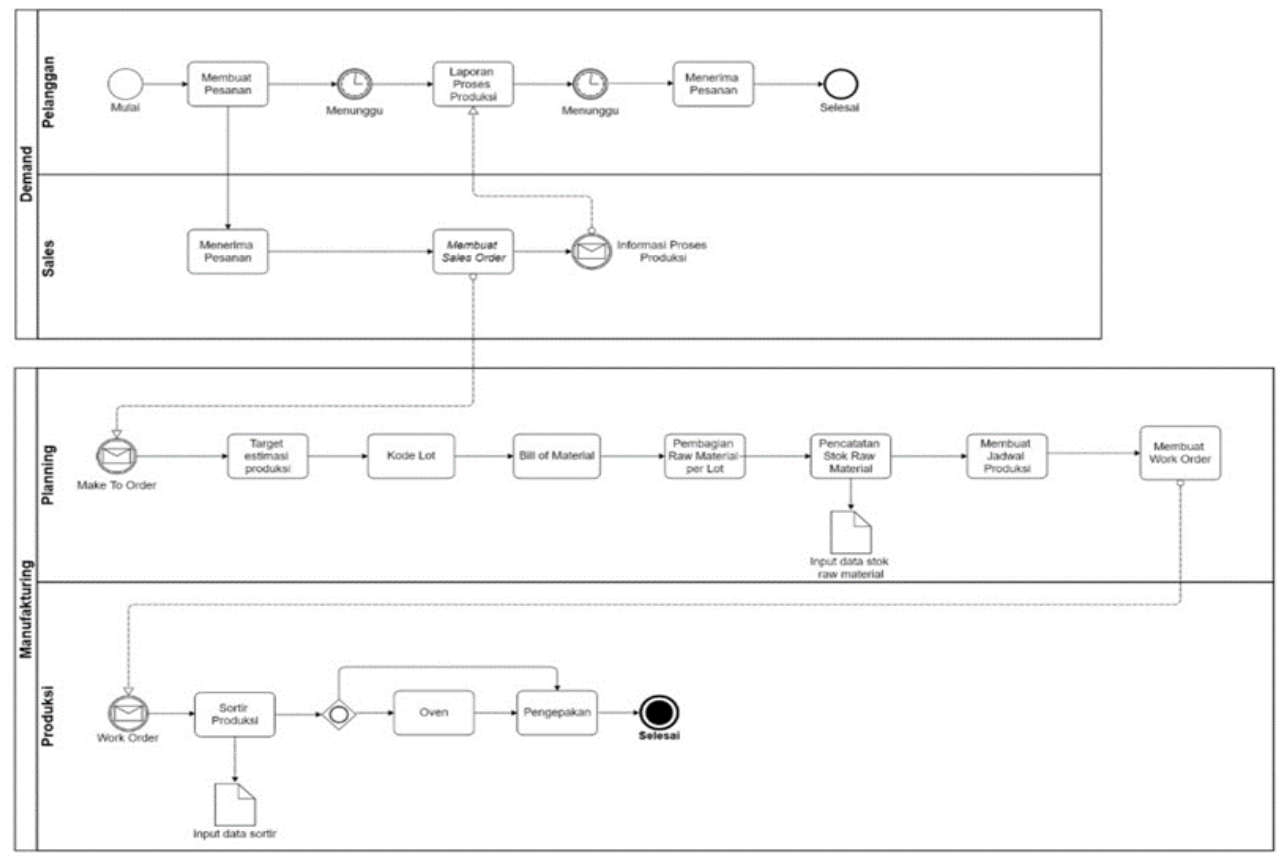

Gambar 7. BPMN MRP

e. Akuntansi

Proses bisnis pembelian bahan baku (raw material) dari bagian produksi ke bagian keuangan. Alur dari gambar 8, dijelaskan sebagai berikut:

1) Bagian produksi melakukan penyediaan bahan baku yang diambil dari supplier;

2) Penyediaan bahan baku dibeli secara kredit atau tunai; 
3) Setelah itu, bukti transaksi pembelian/ faktur diberikan kepada bagian keuangan;

4) Bahan baku/raw material tersedia;

5) Bukti transaksi diterima oleh bagian keuangan;

6) Bagian keuangan mencatat bukti transaksi;

7) Bukti transaksi dilakukan secara tunai atau kredit/angsuran;

8) Jika transaksi tunai maka akan dicatat mengurangi kas dan jika secara kredit/angsuran maka dicatat akan menambah hutang.;

9) Bagian keuangan melakukan penjurnalan.

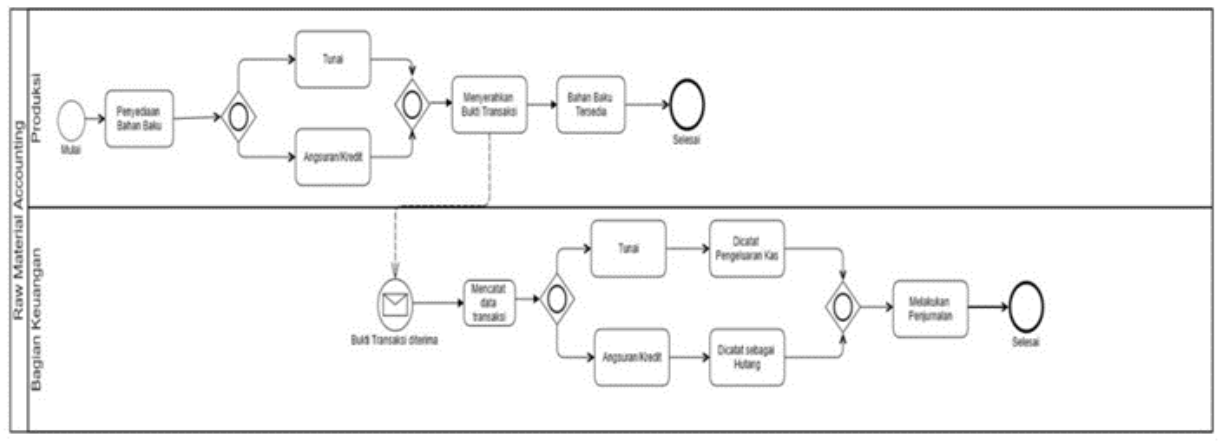

Gambar 8. BPMN Pembelian Bahan Baku

Jika proses penjualan dilakukan dengan sistem piutang (gambar 9) maka alur sebagai berikut:

1) Pelanggan melakukan purchasing order;

2) Mengajukan piutang kepada perusahaan;

3) Kemudian pengajuan piutang disetujui oleh sales;

4) Sales mengkonfirmasi dan membuat bukti transaksi piutang dengan bagian keuangan;

5) Kemudian sales melanjutkan ke bagian gudang untuk melakukan pengecekan dan pengiriman produk;

6) Di bagian keuangan kemudian mencatat piutang sebagai pengurangan kas;

7) Melakukan proses penjurnalan. 


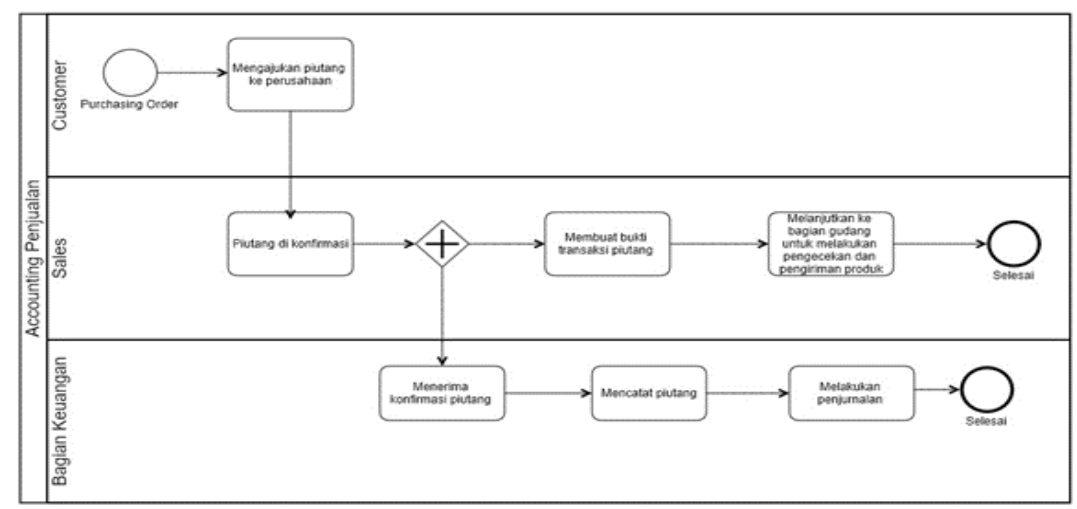

Gambar 9. BPMN Penjulan Sistem Piutang

Proses pembayaran piutang dari customer ke sales dan dilanjutkan ke bagian keuangan:

1) Sales menerima data piutang pelanggan;

2) Kemudian menyerahkan tagihan piutang dan melakukan pengecekan data piutang pelanggan ke bagian keuangan;

3) Lalu pelanggan melakukan pembayaran piutang;

4) Sales menerima uang pembayaran piutang;

5) Sales memberikan uang pembayaran piutang ke bagian keuangan;

6) Bagian keuangan mencatat penambahan kas/pemasukan dan melakukan proses penjurnalan;

7) Sales memberikan kuitansi pelunasan kepada pelanggan;

8) Pelanggan menerima kuitansi pelunasan.

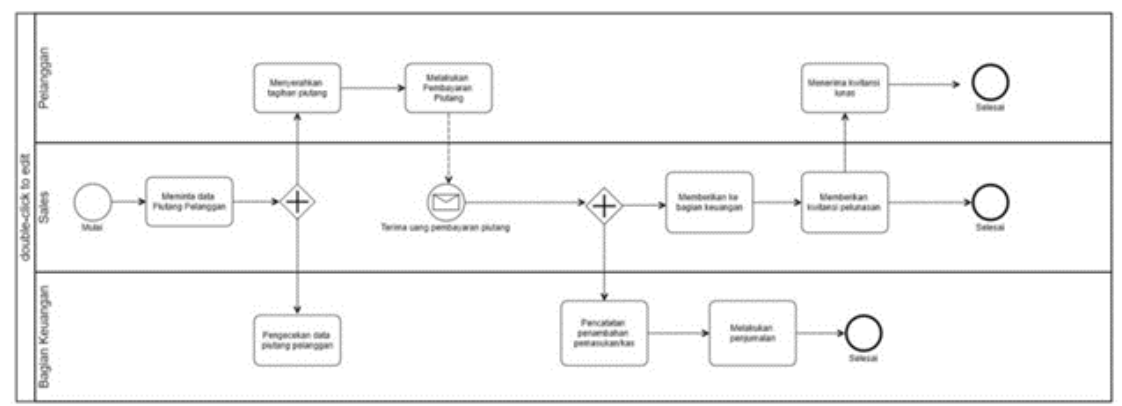

Gambar 10. BPMN Pembayaran Piutang 


\section{Analisis Gap}

Analisis GAP atau analisis kesenjangan merupakan salah satu langkah yang sangat penting dalam tahapan perencanaan atau tahap evaluasi kerja. Metode ini salah satu metode yang umum digunakan dalam pengelolaan manajemen internal suatu lembaga (Ikhwan, 2020; Hakam, 2017; Muchsam, Falahah, \& Saputro, 2011). Analisis GAP dibuat berdasarkan BPMN dengan menggunakan aplikasi dan fitur yang ada di Odoo. Tabel 1 merupakan analisis GAP di CV Indococo Pasific.

Tabel 1. Analisis GAP

\begin{tabular}{|c|c|c|c|c|c|c|}
\hline \multirow{2}{*}{ No } & \multirow{2}{*}{ Kondisi Saat ini } & \multirow{2}{*}{ Kebutuhan } & \multicolumn{3}{|c|}{ Fulfillment } & \multirow{2}{*}{ Solusi } \\
\hline & & & $\mathrm{N}$ & $\mathrm{P}$ & $\mathrm{F}$ & \\
\hline 1 & $\begin{array}{l}\text { Bagian proses sortir } \\
\text { barang digunakan } \\
\text { untuk memilah } \\
\text { bahan baku yang } \\
\text { perlu dioven atau } \\
\text { langsung di- } \\
\text { packing }\end{array}$ & $\begin{array}{l}\text { Sistem informasi Odoo } \\
\text { harus mampu mendata } \\
\text { dan men-generate } \mathrm{QR} \\
\text { code untuk memberi } \\
\text { kode bahan baku yang } \\
\text { langsung di-packing }\end{array}$ & & $\sqrt{ }$ & & $\begin{array}{l}\text { Membuat } \\
\text { modul untuk } \\
\text { melakukan } \\
\text { generate } \mathrm{QR} \\
\text { Code bahan } \\
\text { mentah }\end{array}$ \\
\hline 2 & $\begin{array}{l}\text { Bagian proses } \\
\text { pengovenan } \\
\text { digunakan untuk } \\
\text { men-tracking data } \\
\text { berat bahan baku } \\
\text { yang dipanaskan } \\
\text { sebelum dan setelah } \\
\text { pengovenan }\end{array}$ & $\begin{array}{l}\text { Sistem informasi Odoo } \\
\text { harus mampu mendata } \\
\text { bahan baku yang masuk } \\
\text { oven dan data } \\
\text { penyusutan setelah } \\
\text { pengovenan }\end{array}$ & & $\sqrt{ }$ & & $\begin{array}{l}\text { Membuat } \\
\text { form/pengukur } \\
\text { an penyusutan } \\
\text { produk }\end{array}$ \\
\hline 3 & $\begin{array}{l}\text { Bagian proses } \\
\text { packing digunakan } \\
\text { untuk mendata } \\
\text { kebutuhan packing } \\
\text { untuk bahan jadi }\end{array}$ & $\begin{array}{l}\text { Sistem informasi Odoo } \\
\text { mampu menampilkan } \\
\text { QR code packing bahan } \\
\text { jadi }\end{array}$ & & $\sqrt{ }$ & & $\begin{array}{l}\text { Membuat } \\
\text { modul untuk } \\
\text { men-generate } \\
\text { QR code } \\
\text { produk jadi }\end{array}$ \\
\hline 4 & $\begin{array}{l}\text { Bagian proses } \\
\text { operasi digunakan } \\
\text { untuk membuat } \\
\text { order produksi, } \\
\text { order kerja, order } \\
\text { pembongkaran, dan } \\
\text { buang order }\end{array}$ & $\begin{array}{l}\text { Sistem informasi Odoo } \\
\text { mampu mengelola semua } \\
\text { proses operasi : order } \\
\text { produksi, order kerja, } \\
\text { order pembongkaran }\end{array}$ & & & $\sqrt{ }$ & \\
\hline 5 & $\begin{array}{l}\text { Bagian proses data } \\
\text { master digunakan } \\
\text { untuk menampung } \\
\text { produk, daftar } \\
\text { kebutuhan material }\end{array}$ & $\begin{array}{l}\text { Sistem informasi odoo } \\
\text { dapat menampung data } \\
\text { produk, BOM, dan pusat } \\
\text { kerja }\end{array}$ & & & $\sqrt{ }$ & \\
\hline
\end{tabular}




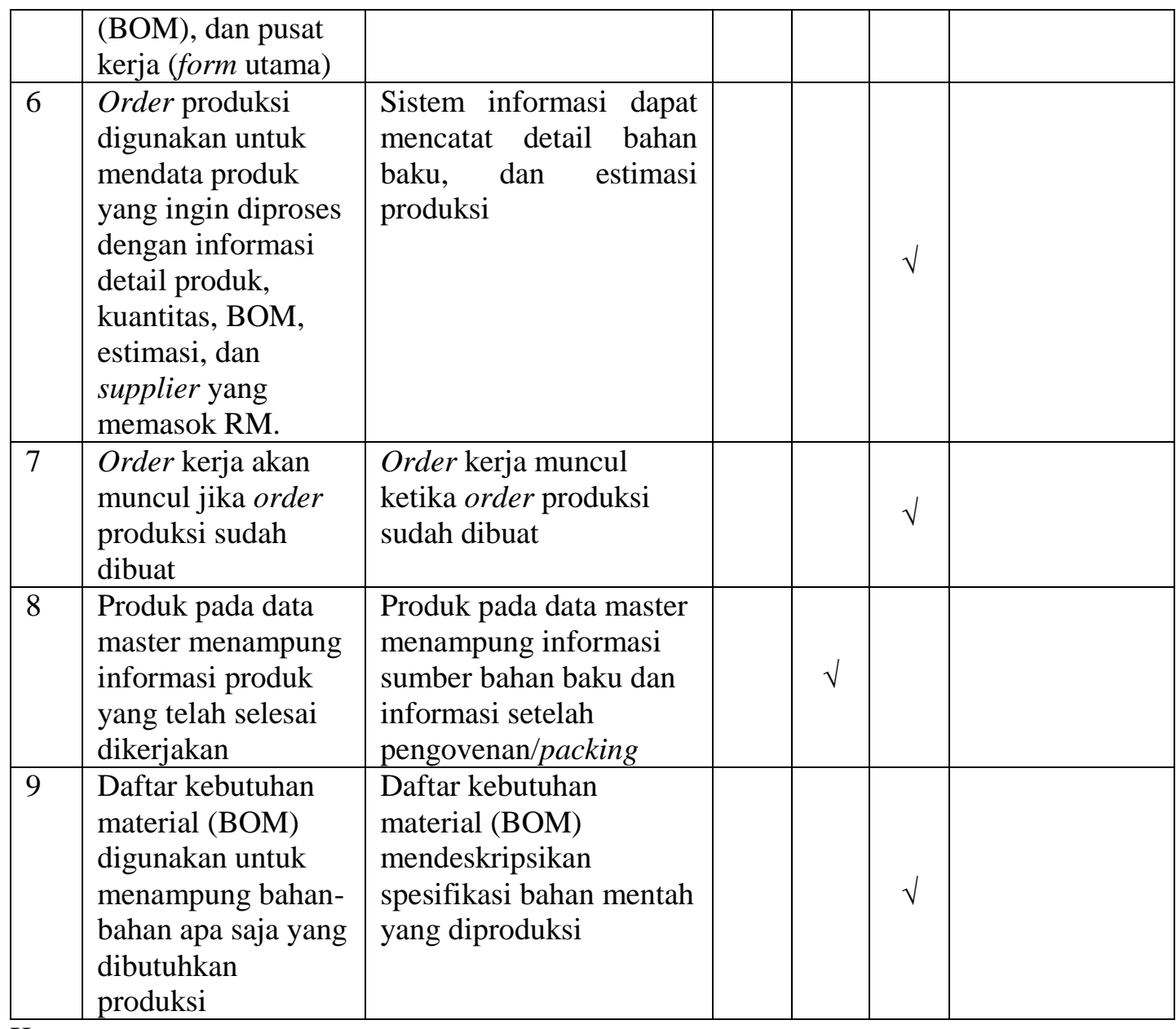

Keterangan:

$\mathrm{N}($ Non $) \quad$ : Kondisi saat ini tidak memenuhi kebutuhan yang disesuaikan dengan Odoo

P (Performing) : Kondisi saat ini sebagian memenuhi kebutuhan yang disesuaikan dengan Odoo

F (Financing) : Kondisi saat ini sudah memenuhi kebutuhan yang disesuaikan dengan Odoo

\section{KESIMPULAN DAN SARAN}

Berdasarkan hasil penelitian pemodelan proses bisnis menggunakan pendekatan Business Process Modelling Notation (BPMN) serta analisis GAP yang telah dilakukan, maka dapat diambil kesimpulan sebagai berikut:

1. Dari bagian proses sortir barang digunakan untuk memilah bahan baku yang perlu dioven atau langsung di-packing, maka solusinya adalah membuat modul untuk melakukan generate QR Code bahan mentah. 
2. Bagian proses pengovenan digunakan untuk men-tracking data berat bahan baku yang dipanaskan sebelum dan setelah pengovenan, maka solusinya membuat form atau pengukuran penyusutan produk.

3. Bagian proses packing digunakan untuk mendata kebutuhan packing untuk bahan jadi, maka solusinya membuat modul untuk men-generate QR code produk jadi.

\section{DAFTAR PUSTAKA}

Badr, N., Hatem A., \& Emad, E. (2017). Business Process Semantic Annotation Suggestions in ERP Systems. Akademia Baru. 1(1): 29-36.

Dumas, M., Marcello, La Rosa, Jan Mendling, \& Hajo, A. Reijers. (2013). Fundamentals of Business Process Management. Fundamentals of Business Process Management.

Hakam, Fahmi. (2017). Analisis Sistem Dan Teknologi Informasi Sebagai Acauan Dalam Perancangan Rencana Strategis Sistem Informasi Dan Teknologi Informasi (Renstra Si/Ti) Di Rumah Sakit Islam Yogyakarta Pdhi. JSI: Jurnal Sistem Informasi (E-Journal) 9(1).

Ikhwan, A. B. (2020). Analisis Perencanaan Strategis Sistem Informasi Dan Teknologi Informasi Menggunakan Framework Ward Dan Peppard Studi Kasus: Fakultas Komputer Umitra Indonesia. Jeda 1(1): 1-12.

Maleyeff, John. 2020. Service Science. Business Process Improvement.

Mirza, Kamanda Satio. (2018). Rancang Bangun Aplikasi Rekrutmen Dan Seleksi Pegawai Berdasarkan Kompetensi Pada RSIA Putri Surabaya. 1-165.

Muchsam, Yoki, Falahah, and Galih Irianto Saputro. (2011). Penerapan Gap Analysis Pada Pengembangan Sistem Pendukung. Seminar Nasional Aplikasi Teknologi Informasi 2011(September 2020): A-94-A-100.

Terminanto, A., \& Hidayanto, A. N. (2018). Implementation and Configurations Open Source ERP in Ecommerce Module (A Case Study on SME). In 8th International Conference on Industrial Engineering and Operations Management, IEOM 2018, , 1224-33.

Zafar, I., Azam, F., Anwar, M. W., Maqbool, B., Butt, W. H., \& Nazir, A. (2019). A Novel Framework to Automatically Generate Executable Web Services from Bpmn Models. In IEEE Access, , 7. 